\title{
Abkürzungen und Symbole im Text
}

\begin{tabular}{|c|c|}
\hline Adj. & Adjektiv \\
\hline Adv. & Adverb \\
\hline afries. & altfriesisch \\
\hline ags. & angelsächsisch (= altenglisch) \\
\hline ahd. & althochdeutsch \\
\hline aisl. & altisländisch \\
\hline Akk. & Akkusativ \\
\hline altfrk. & altfränkisch \\
\hline altfrz. & altfranzösisch \\
\hline altind. & altindisch \\
\hline altir. & altirisch \\
\hline altiran. & altiranisch \\
\hline altslaw. & altslawisch \\
\hline am. & amerikanisch \\
\hline an. & altnordisch \\
\hline as. & altsächsisch (= altniederdeutsch) \\
\hline bair. & bairisch (sprachlich-ethnographisch) \\
\hline Dat. & Dativ \\
\hline dt. & deutsch \\
\hline engl. & englisch \\
\hline finn. & finnisch \\
\hline fries. & friesisch \\
\hline frnhd. & frühneuhochdeutsch \\
\hline frühahd. & frühalthochdeutsch \\
\hline frz. & französisch \\
\hline gall. & gallisch \\
\hline Gen. & Genitiv \\
\hline germ. & germanisch \\
\hline got. & gotisch \\
\hline griech. & griechisch \\
\hline hd. & hochdeutsch \\
\hline hebr. & hebräisch \\
\hline idg. & indogermanisch (= indoeuropäisch) \\
\hline Ind. & Indikativ \\
\hline ind. & indisch \\
\hline it. & italienisch \\
\hline kelt. & keltisch \\
\hline Konj. & Konjunktiv \\
\hline lat. & lateinisch \\
\hline md. & mitteldeutsch \\
\hline mhd. & mittelhochdeutsch \\
\hline mnd. & mittelniederdeutsch \\
\hline mnl. & mittelniederländisch \\
\hline nd. & niederdeutsch \\
\hline
\end{tabular}




$\begin{array}{ll}\text { ndl. } & \text { niederländisch } \\ \text { nhd. } & \text { neuhochdeutsch } \\ \text { Nom. } & \text { Nominativ } \\ \text { nord. } & \text { nordisch } \\ \text { obersächs. } & \text { obersächsisch } \\ \text { od. } & \text { oberdeutsch } \\ \text { österr. } & \text { österreichisch } \\ \text { Pers. } & \text { Person } \\ \text { Pl. } & \text { Plural } \\ \text { rom. } & \text { romanisch } \\ \text { russ. } & \text { russisch } \\ \text { Sg. } & \text { Singular } \\ \text { slaw. } & \text { slawisch } \\ \text { sowj. } & \text { sowjetisch } \\ \text { wgerm. } & \text { westgermanisch } \\ \text { * } & \text { erschlossene oder konstruierte objektsprachliche Einheit } \\ \neq & \text { ist nicht gleich mit ...; steht in Opposition zu ... } \\ <> & \text { graphematische Einheit } \\ \text { // } & \text { phonematische Einheit } \\ \text { [] } & \text { phonetische Transkription } \\ \text { p } & \text { stimmloser dentaler Engelaut (Reibelaut, Frikativ) } \\ \text { d } & \text { stimmhafter dentaler Engelaut (Reibelaut, Frikativ) } \\ \text { X } & \text { stimmloser palatoveraler Engelaut (Reibelaut, Frikativ) }\end{array}$

